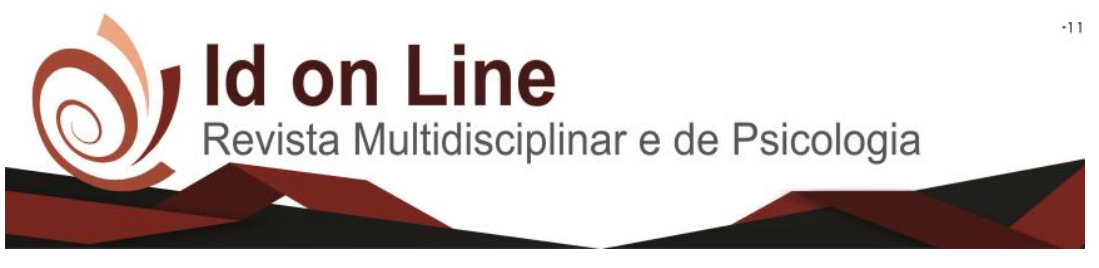

DOI: 10.14295/idonline.v13i46.2010

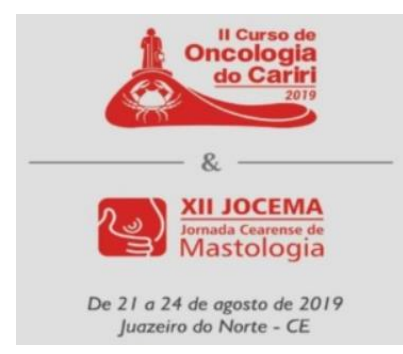

Resumo

\title{
CUIDADOS PALIATIVOS: QUALIDADE DE VIDA E PRESERVAÇÃO DA DIGNIDADE HUMANA
}

\author{
Paula Gabriella de Sousa Araújo ${ }^{1}$; Helen Fernanda de Oliveira Sousa ${ }^{1}$
}

Introdução: Convencionalmente o termo palliun significa manto, coberta, manifestando a ideia de que os cuidados paliativos estão embasados não no ato de curar e sim no sentido mais amplo do cuidado. Nesse processo que abrange principalmente os pacientes oncológicos, a morte é vista como a terminalidade do corpo físico, uma etapa normal da vida, fato que resgata a importância da preservação do bem-estar e dignidade humana. Nessa perspectiva, indivíduos em situações terminais recebem assistência multidisciplinar que garantem controle da dor física e dos problemas psicossociais. A equipe é composta de acordo com as necessidades de cada paciente e normalmente é instituída por médico, enfermeiro, psicólogo, farmacêutico, fisioterapeuta, nutricionista, assistente social, dentista, terapeuta ocupacional e assistente espiritual que trabalham em conjunto para beneficiar tanto o paciente em sofrimento quanto a família. Objetivo: Acatar a relevância dos cuidados paliativos na preservação da qualidade de vida do paciente no que se refere aos âmbitos sociais, psicológicos e espirituais. A conservação da dignidade até o fim da vida é um princípio moral baseado nos direitos humanos, desse modo reconhecer o paciente terminal não apenas como uma doença é o passo inicial para um tratamento humanizado e efetivo. Métodos: Foi elaborado a partir de revisão de literatura obtida por análise de artigos científicos que tem como base de dados Google Acadêmico e SCIELO. Os principais descritores utilizados foram cuidados paliativos, qualidade de vida e pacientes terminais. Resultados: Os pacientes terminais sob cuidados paliativos conseguem obter melhorias nos sintomas de sua doença, além de desfrutar da sensação de não ser um incômodo para seus cuidadores, já que sua capacidade funcional e autonomia são beneficiados. Conclusão: $O$ bem-estar físico, mental, social e espiritual são direitos inegáveis a qualquer ser humano que esteja ou não passando por algum sofrimento. Pacientes oncológicos sem respostas a nenhuma terapia convencional merecem desfrutar o restante de suas vidas de forma plena, sem dores e preocupações adicionais. Os cuidados paliativos garantem alívio para as aflições do corpo e da alma e trabalham de forma interdisciplinar para que a família e/ou cuidadores sejam assistidos com a mesma cautela e preocupação. Desse modo, tal processo permite que a morte deixe de ser um paradigma e passe a ser vista de forma humanizada.

Palavras-Chave: Cuidados paliativos. Pacientes oncológicos. 


\section{Referências}

ALVES, Márcia Lúcia Sousa Dias; JARDIM, Maria Helena de Agrela Gonçalves; FREITAS, Otília Maria Silva. Sofrimento do doente oncológico em situação paliativa. Revista de enfermagem referência, n. 8, p. 115-124, 2012.

CARDOSO, D. H. et al. Cuidados paliativos na assistência hospitalar: A vivência de uma equipe multiprofissional. Texto Contexto \& Enfermagem, 22 (4), 1134-41. 2013.

FRAGA, Fabiana; DE VILAS BOAS, Rafaela Fernanda Oliveira; DOS ANJOS MENDONÇA, Adriana Rodrigues. Significado, para os médicos, da terminalidade da vida e dos cuidados paliativos. Revista Bioética, v. 20, n. 3, p. 514-519, 2012.

GOMES, Ana Luisa Zaniboni; OTHERO, Marília Bense. Cuidados paliativos. Estudos avançados, v. 30, n. 88, p. 155-166, 2016.

HERMES, Hélida Ribeiro; LAMARCA, Isabel Cristina Arruda. Cuidados paliativos: uma abordagem a partir das categorias profissionais de saúde. Ciência \& Saúde Coletiva, v. 18, p. 2577-2588, 2013.

SILVA, Patricia Blasco et al. Controle dos sintomas e intervenção nutricional. Fatores que interferem na qualidade de vida de pacientes oncológicos em cuidados paliativos. Revista Dor, v. 11, n. 4, p. 282-288, 2010.

WITTMANN-VIEIRA, Rosmari; GOLDIM, José Roberto. Bioética e cuidados paliativos: tomada de decisões e qualidade de vida. Acta paulista de enfermagem, v. 25, n. 3, p. 334-339, 2012. 